\title{
Megalithic Pochampad: The Skeletal Biology and Archaeological Context of an Iron Age Site in Andhra Pradesh, India
}

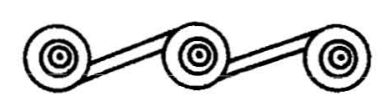

KENNETH A. R. KENNEDY

Iron technology EMERged IN South Asia from regional Copper Age (Chalcolithic) and Bronze Age (Harappan) traditions by 1000 B.C., replacing the dominance of these earlier metallurgical industries at different times prior to the dawn of the Early Historic period (Nagaraja Rao 1971, 1981). Marking the final "Age" of Indian prehistory, iron is uncovered in the archaeological assemblages of the Gandharan Grave Culture of northern Pakistan (1000-300 B.C.), at Pirak and other sites on the Kachi Plain of Pakistan's Indus Valley (by 900 B.C.), with the Painted Grey Ware cultural tradition extending from Baluchistan in western Pakistan to Uttar Pradesh in northern India (900-300 B.C.), and with the "megalithic complex" that spread from the Himalaya foothills southward to peninsular India and Sri Lanka from the early second millennium B.C. in Kashmir to c. A.D. 50 in south India (Agrawal 2000; Chakrabarti 1992; Deo 1985; Kennedy 2000a:326-357, 2000c; Leshnik 1974; Possehl and Rissman 1992; Possehl and Gullapalli 1999) (Fig. 1).

Megaliths are stone monuments visible on the landscape as alignments of standing stones, single stone slabs supported by several boulders to form an enclosed space (dolmens, dolmenoid cists), single or grouped upright standing stones (menhirs), arrangements of large boulders in a circle, and cairns of heaped rubble (Fig. 2). Some above-ground or shallowly buried dolmenoid cists had "port holes" or passages allowing for access of grave goods, food, or additional skeletal remains into the burial chamber. These hallmarks of the megalithic complex of the Indian Iron Age are frequently associated with burials in subterranean stone cists within which human skeletal remains are recovered with iron implements and horse trappings, distinctive red and black wheel-turned and fired ceramic wares, and faunal and floral remains indicative of village farming and pastoral socioeconomic traditions, preserving in certain cultural aspects the lifeways of pre-Iron Age food-producing populations. These megalith builders later became culturally amalgamated with urban-based populations of the Early Historic

Kenneth Kennedy is a professor in the Ecology and Environmental Biology Department at Cornell University, Ithaca, NY.

Asian Perspectives, Vol. 41, No. 1 (C) 2002 by University of Hawai'i Press. 

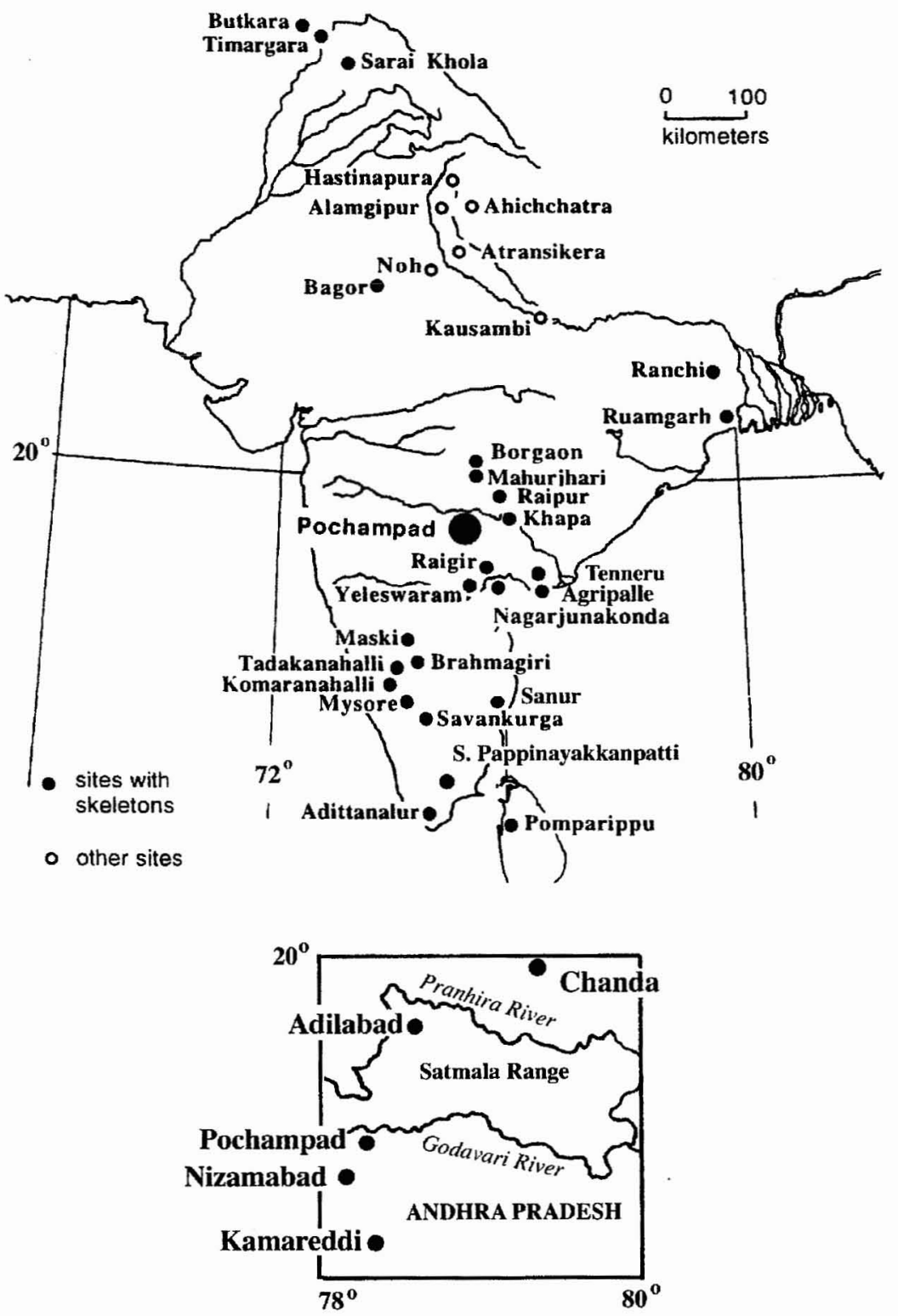

Fig. 1. South Asian Iron Age sites with inset of the location of the Pochampad site.

period who introduced the classical elements of Hindu and Buddhist civilization, although some geographically marginal tribal peoples have continued erecting megalithic structures in association with their funerary rites to the present day.

Of the over 1400 megalithic sites recorded from the subcontinent in 1985, 1116 are from peninsular India (Deo 1985). Since 1820, when their archaeological value was first recognized (Babington 1823), over 239 had been excavated, often by treasure hunters rather than by trained archaeologists. Many of these sites contained preserved human skeletons, but the number of published scientific 


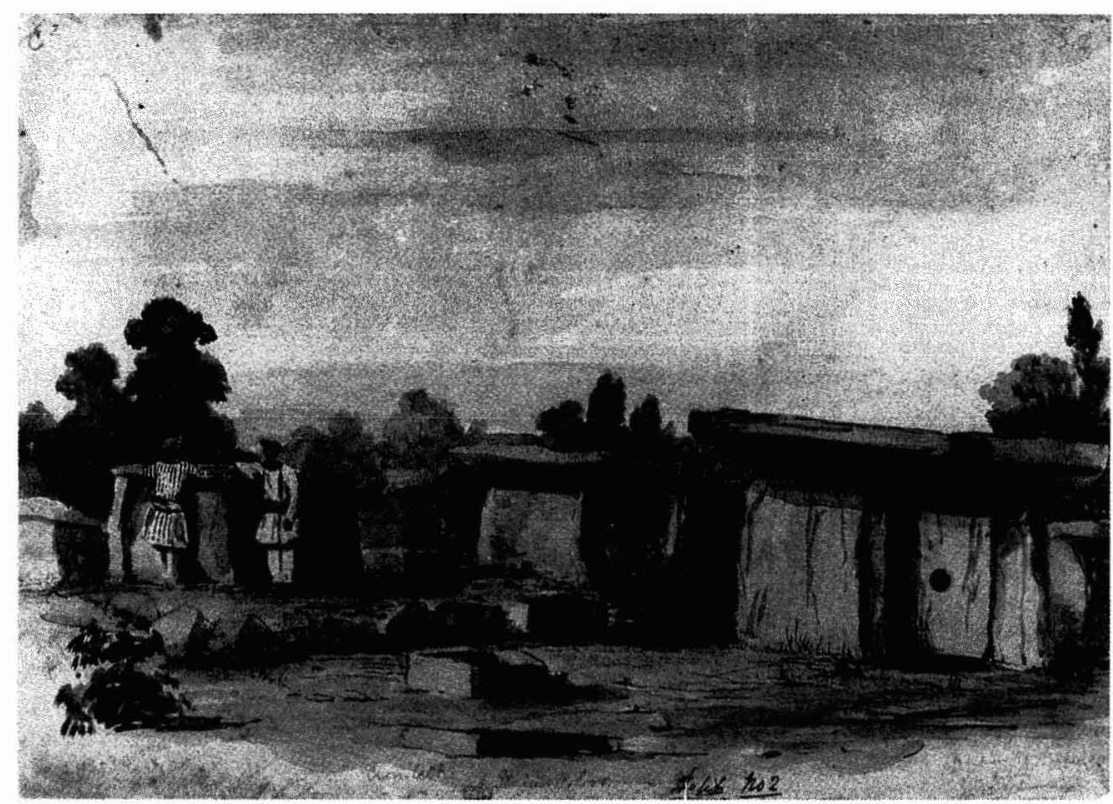

Fig. 2. Iron Age “domenoid cists” at Stayun Kaloor near Nagpur, India, painted by J. H. RivettCarnac (1872, pl. 2). Called "cromlechs" by the artist, this term has become obsolete in archaeology. Depicted here are stone slabs supported on upright stone walls that served as burial chambers; the holes allowed survivors of the deceased to insert grave goods and possibly food.

studies of these remains is less than 30 (Kennedy 2000a:343; Kennedy and Caldwell 1984; Rao 1988) (Table 1). Anatomical data obtained from laboratory analyses by trained biological anthropologists of human skeletal remains from archaeological localities provide information about earlier lifeways and palaeodemographic aspects of extinct populations unobtainable from the records of artifacts, stratigraphy, and texts. Not only is the biological anthropologist able to discern evolutionary trends and movements of populations, but laboratory analysis of osseous and dental structures shed light on the profiles of earlier peoples with respect to their rates of mortality, morbidity, fertility and fecundity, patterns of ontogenetic growth and development, nutritional status, health, and disease. Evidence of accidental or inflicted trauma, population density, and habitat preference also emerge from rigorous scientific analysis. And determination of degrees of genetic affinities of one ancient population with another and geographically and temporally more distant enclaves remains a critical feature of modern scientific approaches to the study of the ancient dead. Laboratory procedures involving comparative analyses of measurements and observations of skeletal specimens provide at present more reliable results than biomolecular data from DNA methods, especially in cases of ancient bone from tropical regions (Kumar et al. 2000).

The present study describes the biological anthropology of Indian Iron Age human skeletal remains recovered in the 1960s from the megalithic burial site of Pochampad in southern India. Challenges for the present author included the examination of poorly preserved bones and teeth that had been carelessly stored and commingled with other prehistoric skeletal series in their repository in India. 
Table i. South Indian and Sri Lankan Megalithic Iron Age Skeletal Series With Published Descriptions

\begin{tabular}{|c|c|c|c|}
\hline SITE & LOCATION & $\begin{array}{l}\text { NUMBER OF } \\
\text { SPECIMENS }\end{array}$ & CITATIONS \\
\hline Adittanalur & Tamil Nadu & 16 & Chatterjee and Gupta 1963 \\
\hline Agripalle & Andhra Pradesh & 4 & Rao et al. 1996 \\
\hline Brahmagiri & Karnataka & 5 & Sarkar 1960,1972 \\
\hline Komaranahalli & Karnataka & 6 & Caldwell and Kennedy 1995 \\
\hline Mysore & Karnataka & 1 & Bain 1980 \\
\hline Nagarjunakonda & Andhra Pradesh & 1 & Gupta et al. 1970 \\
\hline Pomparippu & Sri Lanka & 14 & Lukacs 1976 \\
\hline Raigir & Andhra Pradesh & 11 & Kennedy 1965, 1990 \\
\hline Sanur & Tamil Nadu & 2 & Bose 1959 \\
\hline Savankurga & Karnataka & 1 & Branfill 1881 \\
\hline S. Pappinayakkanpatti & Tamil Nadu & 1 & Walimbe and Selvakumar 1998 \\
\hline Tadakanahalli & Karnataka & 3 & Caldwell and Kennedy 1995 \\
\hline Yeleswaram & Andhra Pradesh & 17 & $\begin{array}{l}\text { Gupta and Dutta 1962; Kennedy } \\
2000 b \text {; Sarkar } 1972\end{array}$ \\
\hline
\end{tabular}

Note: This list does not include South Asian Iron Age sites from the Gandharan Grave Culture, from Pirak and vicinities on the Kachi plain, from sites associated with the Painted Grey Ware cultural tradition or megalithic Iron Age sites in parts of India outside of the peninsular region in which Pochampad is located. For details of other Indian Iron Age sites, see Kennedy 2000a: $12-13,326-357$.

There was also the frustration of interpreting three sets of excavation records containing inconsistent notations, as well as the creation of a catalog that correctly included the actual skeletal specimens from Pochampad. However, this effort seemed necessary given the relative paucity of human skeletal series from Indian Iron Age sites and the need for clearer insights into the lifeways of those South Asian populations, which survived prior to their acculturation into the traditions of the Early Historic period, in peninsular South Asia.

\section{ARCHAEOLOGICAL CONTEXT AT POCHAMPAD}

Pochampad (or Pochampadu) is an Iron Age burial site with megalithic stone circles situated on the right bank of the Godavari River in Andhra Pradesh, southern India ( $78^{\circ} 20^{\prime}$ East, $18^{\circ} 50^{\prime}$ North). Some archaeologists place the site in Adilabad district (Indian Archaeology - A Review (IAR) 1963-1964, 1964-1965, 1966-1967; Leshnik 1974; Rao 1988) while others locate it in adjacent Nizamabad district (Alur 1979; Krishna Sastry 1983). An Iron Age habitation area $1.6 \mathrm{~km}$ upstream on the opposite bank is associated with the Pochampad burial site on the basis of shared ceramic styles, iron implements, and faunal remains, however this connection cannot be established with certainty. During the final centuries of the Iron Age in this part of India, it was customary for burial and habitation localities to be geographically separated by short distances. There are no radiometric or thermoluminescent dates available for Pochampad, but Roman coins found at other southern Indian megalithic burial sites in direct association with archaeological artifacts of similar ceramic pattern and iron implements suggest that Pochampad was used as a burial site between c. 300 B.C. and A.D. 50 (Wheeler 1947-1948). 
Reconstucting the history of excavations at Pochampad in the 1960 s relies upon two sets of published sources: (1) the reports of the Anthropological Survey of India, New Delhi, IAR for 1963-1964, 1964-1965, and 1966-1967; (2) an account in Krishna Sastry's (1983:82-83) book, The Proto and Early Historical Cultures of $A$. P., written nearly 20 years after the Pochampad excavations prior to his appointment as director of the Department of Archaeology and Museums, Government of Andhra Pradesh, Hyderabad. A third source of information is an unpublished report by a Mr. P. R. Murty of Hyderabad written between 1963 and 1965. The present author is familiar with these sources as well as with the human skeletal remains housed at the Department of Archaeology and Museums. Most, but not all of these bones, bear on their surfaces catalog numbers inscribed in black India ink. But what might appear to be adequate documentation of the individual skeletal specimens and their burial contexts is flawed by numerous inconsistencies between the published and unpublished accounts as well as by those human remains that have been salvaged and identified according to their archaeological contexts. This was a problem that this investigator and his associates could only partially resolve given the absence of additional field and museum data and conflicting recollections about the Pochampad excavations offered by those senior Indian archaeologists who had been involved in work at the site. A brief description of Pochampad by B. R. Subrahmanyam (1987:15) further obscures the actual ruins and burial discoveries at Pochampad when he writes in an article published some twenty years after the excavations that "At Pochampad a total of 8 excavated graves (of which) 6 are pits with or without cairns and 3 are cists with or without port-holes. Some of the pits contained extended inhumations: particularly interesting is Megalith 7 (Megalith I?) which contained two skeletons of adults and also one of a horse" (words in parentheses are inserted by the present writer). Unfortunately the problem of maintenance of accurate records and low standards of curation of human burials persists in some South Asian research facilities, in part a reflection of a lack of interest in these remains given the greater importance ascribed to the recovery and curation of cultural objects.

Because of the threat of submergence of Pochampad and neighboring Iron Age megalithic sites in this locality by construction of a dam across the Godavari River, salvage efforts were carried out during field seasons between 1963 and 1967 under the supervision of M.A.W. Khan, then director of the Department of Archaeology and Museums, Hyderabad (IAR 1963-1964:1, 1964-1965:1, 1966-1967:1). Faunal remains recovered from the burial site during the 1971 and 1972 field seasons were identified as domesticated species of sheep and goats (Capridae, Ovis vignei), cattle (Bos indicus), and horse (Equus cabalus) (Alur 1979).

The first excavation in 1963 was within a double circle of 14 untrimmed granite boulders, some $3.6 \mathrm{~m}$ in diameter, surrounding a rectangular pit $1.8 \mathrm{~m}$ in depth and oriented in a north-south direction. Potteries of classical megalithic Iron Age Black-and-Red ware as well as all-black and all-red wares were found in the pit and vicinity along with iron javelins, daggers, and hatchets. Parallel-sided stone blades, points, and lunate-shaped microlithic tools were scattered over the surface of the excavation area that was labeled Megalith I. Additional finds of iron daggers, copper hilts, and small terracotta figurines were recovered at this same locality during the 1964-1965 field season. Human skeletal remains were recovered during these two periods of excavation. 
Megalith II at Pochampad was excavated during the 1966-1967 field season. This was a single circle of 19 closely arranged granite boulders, some $10.6 \mathrm{~m}$ in diameter. They surrounded a central pit with dimensions of 2.16-by-1.68 m cut along a north-south direction. Accompanying human skeletons and bones of a horse were an iron chisel and sickle, pottery dishes, pots and bowls, and rubble scattered between the boulders and into the center of the burial pit.

Megalith III, a single circle of 14 boulders, appears to have been opened during the same field season of 1966-1967. Its subterranean chamber measured 2.85-by$2.09 \mathrm{~m}$. Within this was discovered a heap of human and faunal skeletal remains and all-red painted pots. This would seem to be the last megalithic structure excavated at Pochampad, but there are labels attached to some of the human skeletal remains deposited at the facility of the Department of Archaeology and Museums in Hyderabad upon which is written in black ink "Megalith IV," a circumstance that remains unclear given the absence of any written account of this deposit.

\section{THE SKELETAL INVENTORY}

Human skeletal and faunal remains from Pochampad were examined in Hyderabad by the author in 1972 and 1988. Labels are marked on some bones with black ink while other specimens are tagged with paper labels, all bearing the full name of the site of their recovery or its abbreviation "P.P.D." The author was able to compile an inventory of human skeletal remains based upon what has been preserved (Table 2). When a comparison of this inventory is made with the notes about the human skeletal remains reported for the site in $I A R$, in Krishna Sastry's

Table 2. Pochampad Skeletal Inventory

\begin{tabular}{|c|c|c|}
\hline SPECIMEN NO. & MEGALITH NO. & DESCRIPTION OF SKELETAL REMAINS \\
\hline $1966,2 / 66$ & I & Portions of a cranial vault. \\
\hline $1966,3 / 66-4 / 66$ & II & Left portion of frontal bone and calvaria. \\
\hline $1966,5 / 66$ & III & $\begin{array}{l}\text { Fragments of cranial bones and loose teeth of } \\
\text { the permanent dentition; two individuals. }\end{array}$ \\
\hline 1964, 1/4 (Kennedy C) & I & $\begin{array}{l}\text { Left half of a maxilla with partially complete } \\
\text { permanent dentition. }\end{array}$ \\
\hline Unlabeled (Kennedy A) & I & $\begin{array}{l}\text { Mandible missing its rami but with partially } \\
\text { complete permanent dentition. }\end{array}$ \\
\hline 1966, 5/6 (Kennedy B1 and B2) & I & $\begin{array}{l}\text { Mandibular and maxillary fragments with } \\
\text { dentition of two individuals; one occipital } \\
\text { bone. }\end{array}$ \\
\hline 1963-64 (no other numbers) & II & $\begin{array}{l}\text { Fragments of maxilla and mandible with } \\
\text { permanent loose teeth and postcranial } \\
\text { bones of several individuals. }\end{array}$ \\
\hline $1966,1 / 4$ & IV & $\begin{array}{l}\text { Skull, separate left mastoid process, two } \\
\text { occipital bones. }\end{array}$ \\
\hline 1966 (no other number) & III & One occipital bone. \\
\hline $1964,3 / 64$ & I or II? & $\begin{array}{l}\text { Fragments of cranial and mandibular bones } \\
\text { and loose permanent teeth. }\end{array}$ \\
\hline
\end{tabular}

Note: Skeletal remains recovered from Megalith IV were not available to the author for examination. 
book published in 1983, and in the unpublished manuscript by Murty, it becomes immediately obvious that some skeletons encountered at the time of excavation are no longer in the series curated in Hyderabad. Furthermore, there are inconsistencies in the published and unpublished accounts.

For Megalith I three burials are reported in IAR 1963-1964 for the first field season at Pochampad in 1963. Based upon Murty's unpublished manuscript, Krishna Sastry (1983:83) notes that, "It appears that the burials were partly disturbed by treasure-hunters. However, the funerary assemblages remained undisturbed." It is impossible to interpret this contradiction of what the archaeologists encountered, but the same author goes on to write, "In the middle of the pit were seen two crushed skulls beside a few bones deposited over the red-ware pots. The skulls were completely crushed, leaving no traces for identification. The mandibles were seen dislodged from their sockets." These specimens bear the catalog entry P.P.D. No. 1964, 1/64. However, the preserved skeletal remains bearing this number include the left half of a maxilla but retain a partially complete permanent dentition (now designated for clarification as "Kennedy C"). Also present is an unlabeled mandible missing its rami but with a nearly complete permanent dentition (now designated for clarification as "Kennedy A"). Megalith II was opened during this initial field season at Pochampad, and teeth and postcranial bones of several individuals labeled P.P.D. 1963-1964, Megalith II, are present in the collection in Hyderabad.

There is no mention of recovery of skeletal remains in the notice of continuing excavations at Pochampad in IAR for 1964-1965, but during this second season Megalith II was reopened and, according to Krishna Sastry (1983:83), "To the extreme left of the pottery were seen 4 skulls in a crushed state. One of the skulls faced upwards, with the frontal region and mandible intact, and the bones lain [sic] in an extended position." These remains include the calvaria and dentition labeled P.P.D. No. 1966, 3/66-4/66 and the left fragment of a frontal bone labeled P.P.D. No. 1966, 3/66, Megalith II.

Five megalithic burials are reported in IAR for 1966-1967, within which two human skeletons, deemed to be an adult male and adult female, were found oriented in an east-west position. This source goes on to report that, "Most of the bones were found in disarticulated positions. The maxilla and mandible with their teeth intact were turned partly to the right. An ivory comb was seen beneath the skull. The ribs and vertbrae, the pelvic girdle, right tibia and fibula, and metacarpals were found mixed up. The burials seem to be secondary. Iron implements, such as a sickle, a chisel and a triangular object of indeterminate use were found between the tibiae." The remains thus described appear to have come from Megalith III, although Krishna Sastry's (1983:83) description of these is much less detailed: "Along the western edge of the pit [in Megalith III] and over the red-ware pots was placed a heap of skeletal remains in a disarticulated state. The crushed skull, separated from the mandible, is placed towards the north and turned to [the] west. On the right side of the skull a heap of animal bones was noticed at a fairly higher level."

Preserved skeletal remains from Megalith III are labeled P.P.D. No. 1966, $5 / 66$, which is represented by a number of cranial fragments and permanent loose teeth of perhaps two individuals. P.P.D. No. 1966, 5/6 consists of maxillary fragments with some permanent teeth in their alveoli plus unlabeled fragments of 
mandibular right and left corpora of two individuals, one with its right molar permanent teeth and the other with its left molar permanent teeth, all in their alveoli. These mandibular fragments are now distinguished for clarification as "Kennedy B1 and B2," respectively. A single occipital bone has an incomplete label marking of P.P.D. No. 1966, Megalith III.

Coming either from Megalith I or Megalith II are pieces of cranial bones and teeth bearing the labels P.P.D. No. 1964, 3/64. There is a mandible in two pieces without teeth in this assortment. Their provenience in the Pochampad burial localities is not recorded in any of the three written sources. Remaining skeletal specimens in the preserved Pochampad series in Hyderabad are from Megalith IV about which no recorded data are available. They are identified as coming from Pochampad only by their markings in ink on the bones. All are cranial fragments, as listed in Table 2 .

The number of individuals represented in this skeletal series is estimated to be over ten. The presence of loose teeth and bone fragments suggest that secondary burial customs were practiced, i.e., the deposition of parts of a skeleton into the megalithic burial chamber by survivors of the deceased individual after the body had undergone considerable disintegration from erosional forces and scavenger activity following death. The length of time that Pochampad served as a burial site is unknown beyond what is estimated for the duration of the Iron Age in this part of India. The problem of commingling has been compounded by not maintaining together the bones of individuals before and after their transport from the site to the holding area in Hyderabad and subsequent mishandling by curators. Indeed, in one wooden crate there was included with the Pochampad specimens facial bones of a juvenile individual, and accompanying these were fragments of sphenoid and maxillary bones. A handwritten note read: "Tenner Exc. 1970. Two fragments of Skull No. 3/70 (undecipherable signature) 20-9-72." A second assemblage of bone fragments from Tenner (or Tenneru), a megalithic burial site $95 \mathrm{~km}$ southeast of Pochampad in Krishna district, Andhra Pradesh, was found mixed into the Pochampad series. In most cases the correct provenience of the skeletal series could be established by the inked markings on the bones themselves, but this exemplifies one of the problems faced by many investigators in South Asia. The skeletons from Tenner have not as yet been described in any published source, but the researcher who initiates this project will now be in a better position to distinguish Tenner skeletons from those of Pochampad!

\section{MORPHOMETRIC ANALYSIS (TABLES 3, 4, AND 5)}

\section{Specimen No. 1966, 2/66, Megalith I}

This young adult female individual is represented by portions of a cranial vault of which major parts of the frontal and parietal bones are preserved (see Tables 4 and 5). The occipital bone and cranial base are missing (Figs. 3 and 4). The proportions of the vault are short and broad and parietal eminences are pronounced. There is a moderately developed median frontal eminence. Parts of the frontal sinus are observable through the broken glabellar area. The forehead is low and bulbous in lateral profile, a feature characteristic of female cranial architecture. Postmortem fractures have occurred along sutural lines so that estimations of 
Table 3. Estimated Means of Living Statures for South Indian Iron Age Skeletons

\begin{tabular}{|c|c|c|c|}
\hline \multirow[b]{2}{*}{ SITE } & \multicolumn{2}{|c|}{ STATURE ESTIMATES $(\mathrm{mm})$} & \multirow[b]{2}{*}{ CITATIONS } \\
\hline & MALES & FEMALES & \\
\hline $\begin{array}{l}\text { Brahmagiri } \\
\text { (Karnataka) }\end{array}$ & $1689(2)$ & - & Sarkar 1972 \\
\hline $\begin{array}{l}\text { Nagarjunakonda } \\
\text { (Andhra Pradesh) }\end{array}$ & $1743(1)$ & $1621(2)$ & Gupta et al. 1970 \\
\hline Yeleswaram & $1754(1)$ & $1673(1)$ & Sarkar 1972; Kennedy 20006 \\
\hline (Andhra Pradesh) & $1763(2)$ & $1674(1)$ & \\
\hline $\begin{array}{l}\text { Pochampad } \\
\text { (Andhra Pradesh) }\end{array}$ & \multicolumn{2}{|c|}{$\begin{array}{c}1799(1) \\
\text { Sex uncertain }\end{array}$} & Present study \\
\hline
\end{tabular}

Note: Estimates of living stature are based upon measurements of long bones of the upper and lower extremities and using the regression formulae for adult males and females of European ancestry, according to Trotter's (1970) methods. For a discussion of these and other Iron Age estimations of living stature from skeletal and modern subjects of the Indian subcontinent, see Baernstein and Kennedy (1990).

degrees of synostoses are difficult. Age of this individual is established by the thickness of the bones of the cranial vault and apparent closure of the sagittal suture at pars verticis. Closure at pars pterica suggests an age of 25 to 30 years at time of death.

\section{Specimen 1966, 3/66, Megalith II}

Portions of the left side of the frontal bone, right and left parietal bones, and the occipital bone are preserved along with the left superior orbital margin (Figs. 3 and 4). The sex of this individual is uncertain, but the gracility of the vault suggests it is female. This estimation is supported by observation of the low to moderate size of the glabellar region and bilateral brow ridges. The forehead is moderately elevated with a vertical profile. The frontal bone supports a prominent median eminence. Temporal lines are clearly marked and do not extend posteriorly to the parietal bones. The vault is short and broad with pronounced parietal eminences of which the right eminence is larger than its left counterpart. Occipital curvature is even, but the occipital bone is broken just superior to the nuchal crests. Postmortem damage has resulted in loss of details of the cranial sutures, but at the bregma synostosis is advanced and suggests that this individual died after 30 years (see Tables 3 and 4).

Distortion of the right side of the vault, due to an earlier faulty attempt at anatomical reconstruction, exaggerates the bieuryonic breadth, but it is probable that brachycrany is a feature of this individual. The nasal root is high and a small preserved segment of the nasal bones indicates that the nasal profile was straight. No pathological features were observable on this specimen.

\section{Unlabeled Specimen (Kennedy A), Megalith I}

This is a mandibular corpus with the permanent teeth in their alveoli but rami are missing (Fig. 5). The median form of the mental eminence is prominent. 


\begin{tabular}{lcc}
\hline & \multicolumn{2}{c}{ SPECIMEN NUMBERS AND SEX } \\
\cline { 2 - 3 } CRANIUM & $1966,2 / 6$, FEMALE & $1966,3 / 66$, FEMALE \\
\hline Glabella-Opisthocranian length (1) & & 170 \\
Biuronic breadth (2) & 125 & 100 \\
Parietal chord (30) & & 113 \\
Occipital chord (31) & 144 & 114 \\
Frontal arc (26) & 6 & 129 \\
Parietal arc (27) & 4.5 & 6.5 \\
Thickness of parietal eminence & KENNEDY A, FEMALE & KENNEDY B1, MALE \\
Thickness of frontal eminence & 34 & \\
\hline MANDIBLE & 47 & 31.5 \\
\hline Symphysis height (69) & 30 & 14 \\
Corpus length (68) & 30 & 13.5 \\
Height of corpus at right M1 (69-1) & 10 & 33 \\
Height of corpus at left M1 & 10.5 & 33 \\
Thickness of corpus at right M1 (69b) & 32.5 & \\
Thickness of corpus at left M1 & 33 & \\
Length of molar row, right (80-3) & 46 & \\
Length of molar row, left & & \\
Length of molar-premolar row, left (80-2) & & \\
\hline
\end{tabular}

1963-1964, MEGALITH II,

HUMERUS

FEMALE

Minimum shaft diameter, AP, right (6)

Minimum shaft circumference, right

Mid-shaft diameter, AP, right (6c)

Mid-shaft diameter, lateral, right (6b)

Diaphyseal index, right

16

61

20

19

80.0

Middle index, right

95.0

1963-1964, MEGALITH II,

RADIUS

SEX UNCERTAIN

Minimum shaft diameter, AP, right

13

Minimum shaft diameter, AP, left

Mid-shaft diameter, lateral, right

Mid-shaft diameter, lateral, left

Mid-shaft circumference, right (5-5)

Mid-shaft circumference, left

Middle index, right

Middle index, left

1964-1964, MEGALITH II, ULNA FEMALE?

Minimum shaft diameter, AP, left

Minimum shaft diameter, lateral, left

Mid-shaft diameter, AP, left (11)

Mid-shaft diameter, lateral, left (23)

Minimum shaft circumference left (3)

Diaphyseal index, left

Platolineal index, left 
TABle 4. (continued)

1963-1964, MEGALITH II,

FEMALE?

Maximum length, left (1)

492

Minimum shaft diameter, AP, right $\quad 27$

Minimum shaft diameter, AP, left $\quad 27$

Minimum shaft diameter, lateral, right $\quad 24$

Minimum shaft diameter, lateral, left 24

Subtrochanteric diameter, AP, right (10) 32

Subtrochanteric diameter, AP, left 25

Subtrochanteric diameter, lateral, right (9) 29.5

Subtrochanteric diameter, lateral, left 32

Mid-shaft diameter, AP, right (8) 29

Mid-shaft diameter, AP, left $\quad 30$

Mid-shaft diameter, lateral, right (7) 25

Mid-shaft diameter, lateral, left $\quad 25$

Head diameter, AP, left (18) 44

Head diameter, lateral, left (19) 43.5

Minimum shaft circumference, right $\quad 85$

Minimum shaft circumference, left $\quad 85.5$

Mid-shaft circumference, right (8) 67

Collo-diaphyseal angle, left $\quad 114$ degrees

Platymeric index, left $\quad 78.1$

Middle index, right $\quad 86.2$

Middle index, left $\quad 83.3$

Pilastric index, right $\quad 116.0$

Pilastric index, left $\quad 120.0$

Popliteal index, right $\quad 112.5$

Popliteal index, left $\quad 112.5$

Head index, left $\quad 202.1$

1963-1964, MEGALITH II,

TIBIA

FEMALE?

Maximum length, left (1)

422

32

34

$\begin{array}{lc}\text { Nutrient foramen diameter, lateral, right } & 22- \\ \text { Nutrient foramen diameter, lateral, left } & 212.5\end{array}$

$\begin{array}{lr}\text { Nutrient foramen diameter, lateral, right } & 22- \\ \text { Nutrient foramen diameter, lateral, left } & 212.5\end{array}$

Minimum shaft diameter, AP, right $\quad 25$

Minimum shaft diameter, AP, left $\quad 25$

Minimum shaft diameter, lateral, right $\quad 19$

Minimum shaft diameter, lateral, left $\quad 18.5$

Mid-shaft diameter, AP, right (8) 28

Mid-shaft diameter, AP, left $\quad 29$

Mid-shaft diameter, lateral, right (9) 19

Mid-shaft diameter, lateral, right (9) 19

Mid-shaft diameter, lateral, left 19

Minimum shaft circumference, right (10b) 72.5

Minimum shaft circumference, left $\quad 73$

Mid-shaft circumference, right $\quad 77$

Mid-shaft circumference, left $\quad 79$

Cnemic index, right $\quad 68.7$

Cnemic index, left $\quad 63.2$

Middle index, right $\quad 67.8$

(Continues) 
TABle 4. (continued)

1963-1964, MEgALITH II,

TIBIA FEMALE?

Middle index, left

Length-thickness index, left

17.3

Crural index, left

86.8

1963-1964, MEGALITH II,

FIBULA

SEX UNCERTAIN

Mid-shaft diameter, AP, right (3-2)

Mid-shaft diameter, AP, left

15.5

Mid-shaft diameter, lateral, right (3-1)

16

Mid-shaft diameter, lateral, left

9

Mid-shaft circumference, right (4)

Mid-shaft circumference, left

42

Minimum shaft circumference, right (4a) 37.5

Maximum shaft circumference, right $\quad 54$

Mid-shaft index, right

58.1

Mid-shaft index, left

62.5

1963-1964, MEGALITH II,

PATELLA

SEX UNCERTAIN

Maximum breadth, right (2) 38

Maximum breadth, left

1963-1964, MEGALITH II,

TALUS

SEX UNCERTAIN

Maximum length, right (1) 54

Maximum length, left $\quad 52$

Maximum breadth, right (2). 41

Maximum breadth, left 40

Maximum height, right (3) $\quad 29$

Maximum height, left $\quad 30$

Trochlea tali length, right (4) 33

Trochlea tali length, left 33

Trochlea tali breadth, right (5) 31

Trochlea tali breadth, left $\quad 30$

1963-1964, MEGALITH II,

CALCANEUS

SEX UNCERTAIN

Maximum length, left (1)

83

Maximum height, left (4)

49

Sustentaculum tali, length, right (5)

41

Sustentaculum tali, breadth, left (6)

45

Note: Measurements are millimeter $(\mathrm{mm})$ units unless indicated otherwise. Numbers in parentheses following the name of the measurement refer to anthropometric codes for standards given in Knussmann (1988). Definitions of measurements not included in this source are in Kennedy et al. 1986. 
Table 5. Odontometric Measurements of the Dentitions*

\begin{tabular}{|c|c|c|c|c|c|c|}
\hline \multirow{4}{*}{$\begin{array}{l}\text { MEASUREMENTS }(\mathrm{mm}) \\
\text { AND INDICES }\end{array}$} & \multicolumn{6}{|c|}{ SPECIMEN NOS. AND SEX } \\
\hline & \multirow{3}{*}{$\begin{array}{c}\text { A } \\
\text { FEMALE }\end{array}$} & \multicolumn{2}{|c|}{$1966,5 / 66$} & \multirow{3}{*}{$\begin{array}{l}\mathrm{C} \\
?\end{array}$} & \multirow{2}{*}{\multicolumn{2}{|c|}{ 1963-64, MEGALITH II }} \\
\hline & & & $\mathrm{B} 1+\mathrm{B} 2$ & & & \\
\hline & & FEMALE & MALES & & MALE & FEMALE \\
\hline \multicolumn{7}{|l|}{ Maxillary Dentition } \\
\hline Rl1 MD & & & & & & 8.5 \\
\hline Ll1 MD & & & & & & 8.1 \\
\hline $\mathrm{R} 12 \mathrm{MD}$ & & & & & & 6.8 \\
\hline $\mathrm{Ll} 2 \mathrm{MD}$ & & & & & & 6.9 \\
\hline $\mathrm{RC} \mathrm{MC}$ & & 7.0 & & & & \\
\hline LC MD & & 6.8 & & & & \\
\hline RP3 MD & & 7.0 & & & & \\
\hline $\mathrm{BL}$ & & 8.4 & & & & \\
\hline RPM3 Index & & 83.33 & & & & \\
\hline LP3 MD & & 7.0 & & & & 9.7 \\
\hline LP3 BL & & 8.4 & & & & 7.0 \\
\hline MPM3 Index & & 83.33 & & & & 138.5 \\
\hline RPM4 MD & & 6.4 & & & & \\
\hline RP4 BL & & 8.1 & & & & \\
\hline PP4 Index & & 79.01 & & & & \\
\hline LP4 MD & & 6.2 & & & & 9.2 \\
\hline LP4 BL & & 8.5 & & & & 7.4 \\
\hline LP4 Index & & 72.9 & & & & 124.3 \\
\hline LM1 MD & & 8.6 & & 9.4 & & 11.0 \\
\hline LM1 BL & & 9.1 & & 10.1 & & 10.9 \\
\hline LM1 Index & & 94.50 & & 93.0 & & 100.9 \\
\hline RM2 MD & & 10.0 & & 9.5 & & \\
\hline RM1 BL & & 11.2 & & 10.9 & & \\
\hline LM2 MD & & & & & & 10.0 \\
\hline LM2 BL & & & & & & 10.5 \\
\hline LM2 Index & & & & & & 102.8 \\
\hline RM2 Index & & 89.28 & & 87.15 & & \\
\hline RM3 MD & & 8.5 & & & & \\
\hline RM3 BL & & 9.5 & & & & \\
\hline RM3 Index & & 89.47 & & & & \\
\hline LM3 MD & & & & & 10.9 & \\
\hline LM3 BL & & & & & 9.6 & \\
\hline KM3 Index & & & & & 113.50 & \\
\hline \multicolumn{7}{|l|}{ Mandibular Dentition } \\
\hline R11 MD & & 6.0 & & & 4.7 & \\
\hline LM1 MD & 4.3 & & & & 4.9 & \\
\hline R12 MD & & & & & 5.7 & \\
\hline L12 MD & 3.9 & & & & 6.0 & \\
\hline $\mathrm{RC} \mathrm{MD}$ & 5.4 & & & & 7.2 & \\
\hline LC MD & 6.0 & & & & & \\
\hline RP3 MD & 6.1 & & & & & \\
\hline RP3 BL & 7.2 & & & & & \\
\hline LP3 MD & 6.2 & & & & & \\
\hline LP4 MD & 5.6 & & & & & \\
\hline LP4 BL & 7.6 & & & & & \\
\hline LP4 Index & 73.6 & & & & & \\
\hline
\end{tabular}


TABLE 5. (continued)

\begin{tabular}{|c|c|c|c|c|c|c|}
\hline \multirow{4}{*}{$\begin{array}{l}\text { MEASUREMENTS }(\mathrm{mm}) \\
\text { AND INDICES }\end{array}$} & \multicolumn{6}{|c|}{ SPECIMEN NOS. AND SEX } \\
\hline & \multirow{3}{*}{$\begin{array}{c}\text { A } \\
\text { FEMALE }\end{array}$} & \multicolumn{2}{|c|}{$1966,5 / 66$} & \multirow{3}{*}{$\begin{array}{l}\mathrm{C} \\
?\end{array}$} & \multirow{2}{*}{\multicolumn{2}{|c|}{ 1963-64, MEGALITH I }} \\
\hline & & \multirow[b]{2}{*}{ FFMALE } & \multirow{2}{*}{$\begin{array}{l}\mathrm{B} 1+\mathrm{B} 2 \\
\text { MALES }\end{array}$} & & & \\
\hline & & & & & MALE & FEMALE \\
\hline RM1 MD & 10.1 & & 10.2 & & & \\
\hline RM1 BL & 10.6 & & 9.5 & & & \\
\hline RM1 Index & 95.20 & & & & & \\
\hline LM1 MD & 10.5 & & 10.6 & & & \\
\hline LM1 BL & 11.1 & & 9.5 & & & \\
\hline LM1 Index & 95.4 & & & & & \\
\hline RM2 MD & 9.6 & & 9.2 & & & \\
\hline RM2 BL & 9.1 & & 8.0 & & & \\
\hline RM2 Index & 105.4 & & & & & \\
\hline LM2 MD & 9.3 & & 9.4 & & & \\
\hline LM2 BL & 8.5 & & 8.6 & & & \\
\hline LM2 Index & 97.8 & & & & & \\
\hline RM3 MD & 10.0 & & 10.5 & & & 11.3 \\
\hline RM3 BL & 9.7 & & 9.5 & & & 10.4 \\
\hline RM3 Index & 103.00 & & & & & 108.60 \\
\hline LM3 MD & 10.5 & & 10.9 & & & \\
\hline LM3 BL & 9.9 & & 10.5 & & & \\
\hline LM3 Index & 106.00 & & & & & \\
\hline
\end{tabular}

$+\mathrm{MD}=$ Mesiodistal diameter; $\mathrm{BL}=$ Buccolingual diameter; $\mathrm{R}=$ Right $; \mathrm{L}=\mathrm{Left} ; \mathrm{I}=$ Incisor; $\mathrm{C}=$ Canine; $\mathrm{P}=$ Premolar; $\mathrm{M}=$ Molar. $\mathrm{P} 3=$ First molar; $\mathrm{P} 4=$ Second molar; Index $=\mathrm{MD} /$ $\mathrm{BL} \times 100$.

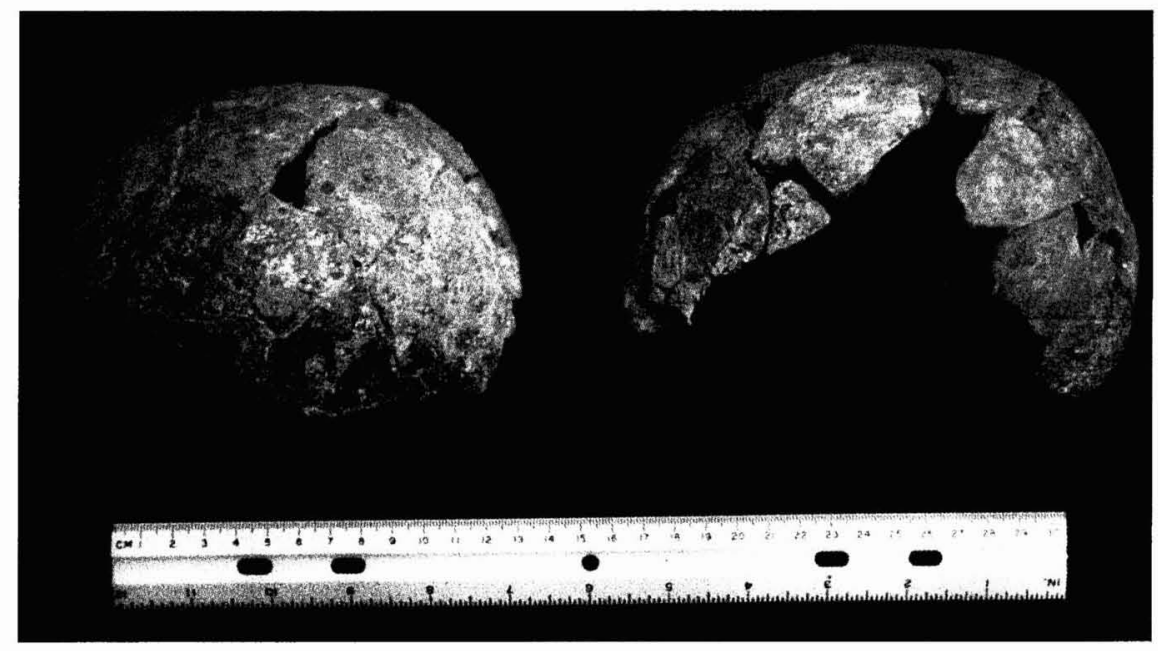

Fig. 3. Cranial vaults of Specimen Nos. 1966, 2/6, Megalith I (left) and 1966, 3/66, Megalith II (right) from Pochampad. Left lateral aspects. 


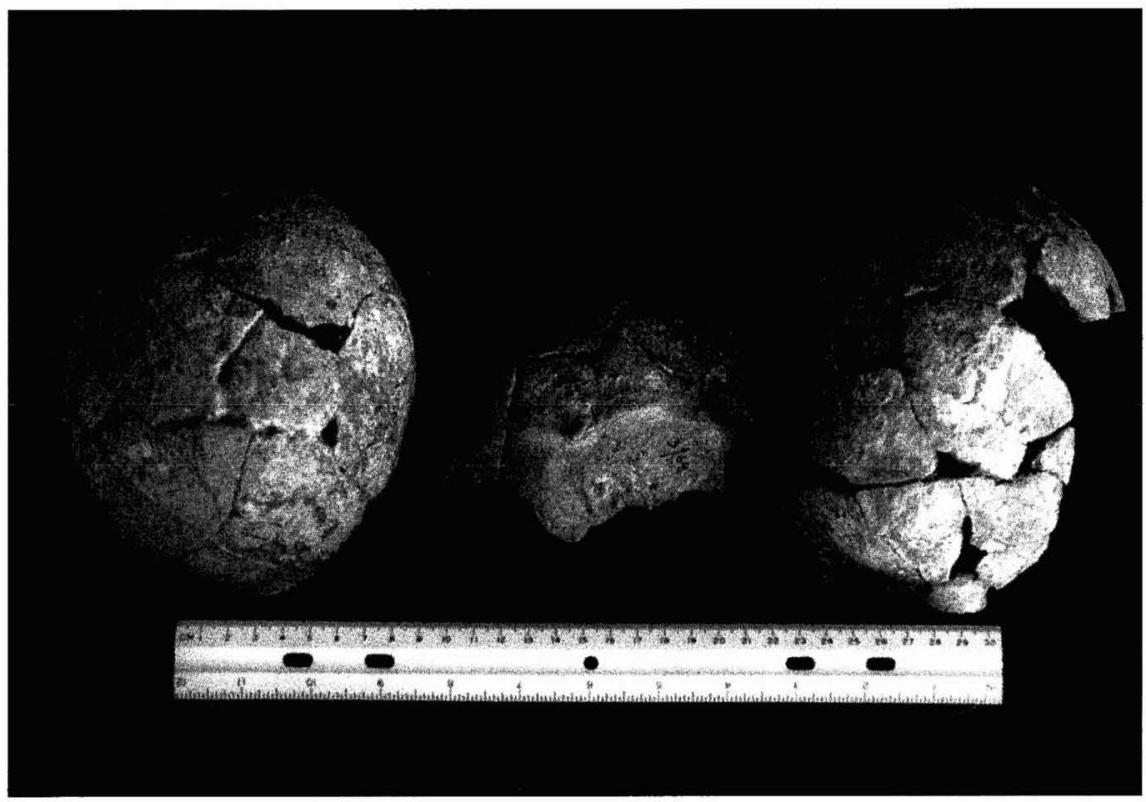

Fig. 4. Cranial vaults of Specimen Nos. 1966, 2/6, Megalith I (left) and 1966, 3/66, Megalith II (right) from Pochampad. Vertical aspects.

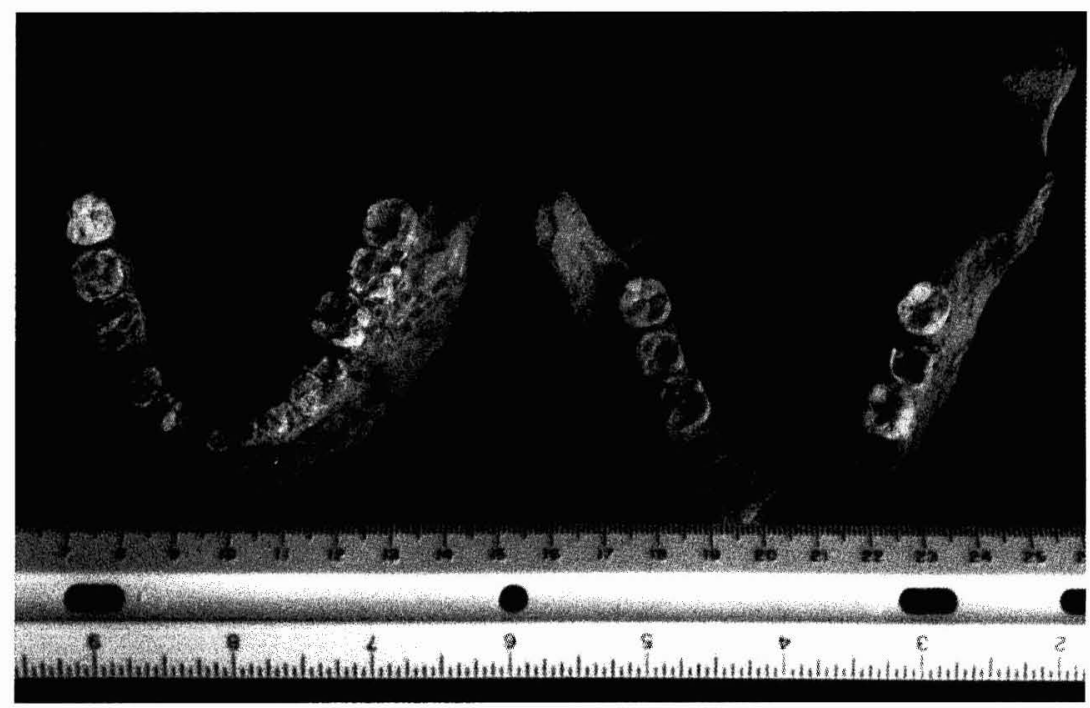

Fig. 5. Mandibles and dentition of Specimen Nos. 1966, Kennedy A (left) and 1996, Kennedy B1 (right) from Pochampad. Occlusal aspects.

Mylohyoid crests are low and genial tubercles are very reduced in size. The rocker jaw condition is present. This may be a female individual.

Enamel crowns are well preserved for all of the teeth with the exception of the left third molar and right lateral incisor. The occlusal surface of the left second 


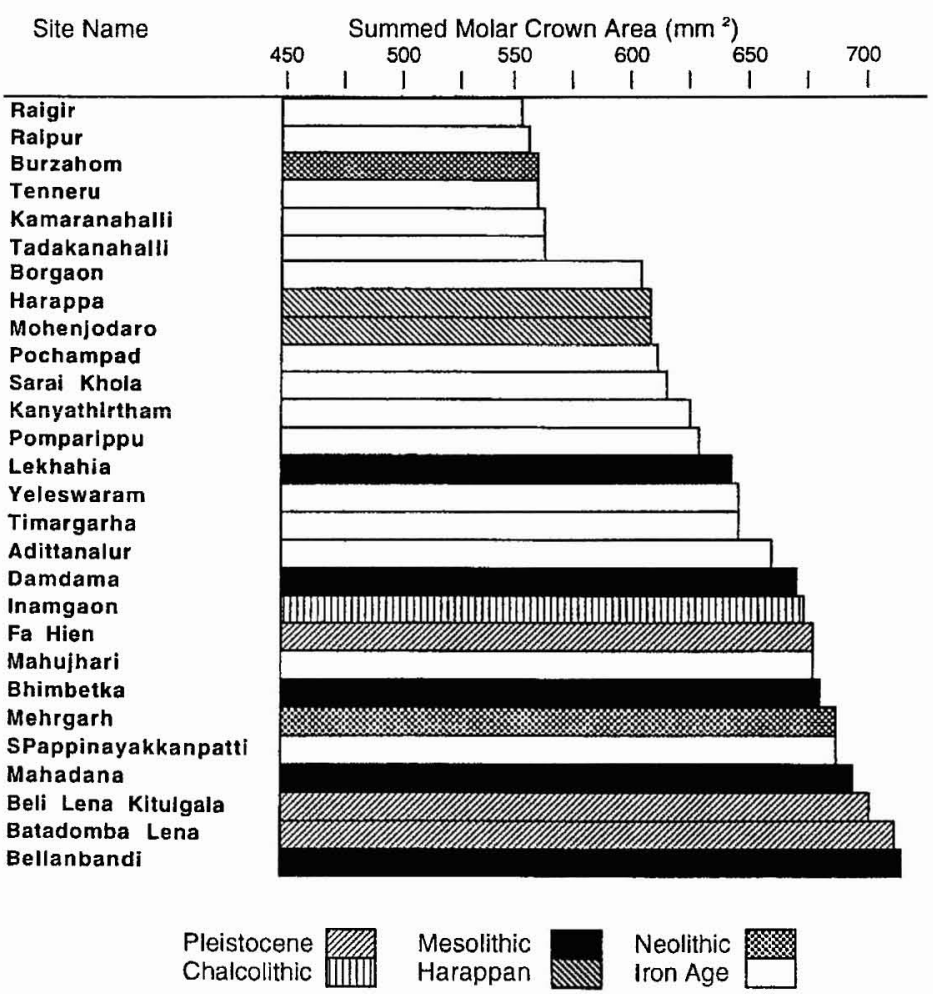

Fig. 6. Summed molar crown areas $\left(\mathrm{mm}^{2}\right)$ of dental samples from 28 prehistoric sites in South Asia. Modified from Lukacs (1983) and Kennedy (1999).

molar was damaged postmortem. The right second premolar was lost postmortem. There is slight damage to the buccal surfaces of the left first and second premolars. Wear is most pronounced for the anterior dentition and to a lesser degree along the occlusal surfaces of the premolar-molar rows, degrees of attrition that suggest an age of 22 to 26 years for Indian Iron Age individuals. A striking feature is the roughness of the occlusal wear pattern, as few smooth enamel surfaces appear on the posterior dentition. These modifications are not indicative of postmortem erosional agencies; rather, they reflect severe tooth chipping before death. Caries, malocclusion, crowding, and calculus are not present. These are relatively small molar teeth as measured by summed molar crown area (594.43 $\mathrm{mm}^{2}$ ) (Fig. 6).

\section{Specimen No. 1966, 5/66, Megalith III}

Cranial bones are fragmentary and no effort was made at reconstruction, the largest piece being a right temporal bone without its mastoid process intact. Two individuals are represented in this deposit. Dental data indicate that one was a young adult since the upper right third molars and lower left third molars are fully erupted but exhibit minimal occlusal wear. With the exception of a right lower central incisor and left lower third molar, all remaining teeth are of the upper 
dentition, some loose and others held in the alveoli of maxillary fragments. Moderate occlusal wear marks the lower left first molar, the adjacent premolars exhibit less wear. The anterior dentition shows greatest loss of occlusal enamel, particularly in the case of the right canine. This differential wear pattern is puzzling since no pathological conditions are observed which could suggest the favoring of one side of the mouth in mastication. Six enamel hypoplasial lines appear on the right canine. The loci of formation of this type of enamel defect observed on the surfaces of tooth crowns provide estimates of the age of the individual at the time of defect development. This condition can result from a temporary interruption of nutrient flow due to such stressors as short- or long-term disease conditions, famine, or metabolic disorders. With relief of such conditions in the immature individuals whose dental crowns and roots are in process of development prior to their eruption, enamel generation is restored. Thus crown development allows estimation of the time of appearance of the enamel hypoplasial lines or pits by measurements of the distances between the cemento-enamel junction to the midpoint of each hypoplasial line. The values for distance and corresponding age of the hypoplasial lines in the canine of this specimen are $8.0 \mathrm{~mm} / 6$ months, $7.2 \mathrm{~mm} / 1$ year and 6 months, $5.8 \mathrm{~mm} / 3$ years and 4 months, $3.2 \mathrm{~mm} / 4$ years, $2.1 \mathrm{~mm} / 5$ years and 2 months, $1.0 \mathrm{~mm} / 6$ years (Goodman and Rose $1991: 288$ ). The upper left first molar and right upper second molar have three cusps respectively, while the lower right third molar has four cusps and the occlusal surface is deeply crenulated.

\section{Specimen No. 1966, 5/6 (Kennedy B1 and B2), Megalith III}

These are unnumbered mandibular corpera with parts of permanent dentition which may belong to two individuals (Fig. 5). One corpus is associated with a left ramus, the other with a right gonial portion. Each corpus contains three molar teeth in their alveoli. Differences in wear patterns of the occlusal surfaces of the teeth, especially for the right and left third molars, suggest that two individuals are present, although size and morphological features are similar for the two corpera. The fragments are large and robust, the gonial portion exhibiting considerable eversion and marked pterygoid muscular attachments. Mylohyoid ridges are large. The corpus-ramus angle of one specimen suggests it belonged to a male individual. Eruption of the third molars in both fragments indicates an adult age, but differences in degree of attrition for these teeth, as well as for the right and left first molars, do not serve to resolve the question of commingling of remains of two persons in the same burial context. The right molar row shows moderate to pronounced occlusal wear for the first and second molars with the enamel preserved along the rims of the occlusal borders with flattened extensions of enamel radiating from the rims into the dentin covering the mass of the surfaces. However, the right third molar shows minimal wear, suggesting its recent eruption. The cusp-groove pattern is $\mathrm{Y}-5$ for this tooth. There is no evidence of caries, malocclusion, or other dental pathological conditions. The left molar row shows low wear of the first molar which has a cusp-groove pattern of Y-5. This tooth has an occlusal pit on the mesio-buccal cusp which was in process of forming a carious lesion since the enamel had been penetrated. This condition does not appear to be a consequence of wear or postmortem damage. The left second molar 
exhibits pronounced wear and some postmortem damage to the dental surface along the cemento-enamel junction where dentin is exposed. This tooth rests at a lower level than the adjacent teeth with elevated and sharp enamel rims. The left third molar shows wear but without exposure of dentin; rather, the occlusal surface is hollowed out to form a small basin with dentin exposed in three small pits, certainly foci for caries. The enamel rim of the left third molar is thick and smooth. The molar teeth have a summed molar crown area of $569.39 \mathrm{~mm}^{2}$, a value indicative of a relatively small molar dentition. Maxillary fragments and six loose teeth were recovered from this burial pit.

\section{Specimen No. 1966, 1/64 (Kennedy C), Megalith I}

This is a left maxillary fragment with the dental row extending from the permanent left incisor distally to the second molar. These teeth are in their alveoli. Crowns were lost postmortem, save for the two molars. Wear is pronounced on the occlusal surface of the first molar, only a thin rim of enamel remaining. The second molar is slightly less worn, the enamel forming a dish-shaped hollow with exposure of dentin along the distal half of the occlusal surface. The maxillary bone fragment does not indicate presence of alveolar prognathism. The left nasal sill is oxycraspedotic. Symphyseal height is $21 \mathrm{~mm}$. There is no evidence of dental or bone pathology in this specimen, an adult of undetermined age at time of death.

\section{Specimen No. 1963-1964, Megalith I}

Commingled with fragments of maxilla and the right half of a mandible are 13 permanent teeth. Occlusal wear is most pronounced on the first premolar and the first and second molars of the upper and lower dentition, but there is less wear on the premolars. However, minimal amounts of dentin are exposed on all of these teeth, a circumstance suggestive of a young adult age. There is the possibility that more than a single individual is represented in this dental series for the reason that some teeth are loose, and those in their maxillary and mandibular alveoli do not fit into an occlusal contact pattern that establishes their assignment to the dentition of one person. There is moderate wear of the anterior teeth of upper and lower dentitions, especially on the right upper canine. Lingual tubercles occur on the upper incisors, but there is no shoveling on the lingual surfaces. Enamel hypoplasial lines are absent in this dental sample.

Postcranial bones bearing this label assigned to them in the field at time of their recovery are commingled remains of several individuals, perhaps as many as three. Paired bones appear to belong to a single individual as indicated by mensural and morphological similarities. Indicators that these are bones of a female individual predominate, but some bones are of undetermined sex. All belong to adults. Of the upper extremities, the right humerus is represented by a complete diaphysis, a crushed right humeral head, and small fragments of the distal end of the shaft. The left humerus is less well preserved. The preserved diaphysis is straight and has an ovoid transverse pattern. Robusticity is low with respect to loci of muscular attachments, the bicipital groove forming a very shallow depression and a weakly elevated crest. The radii are preserved as portions of proximal diaphyses which are 
straight. The radial tuberosities are low but extend $29.5 \mathrm{~mm}$ on both shafts. Interosseous lines are elevated and sharp, and the transverse sections at the midshaft are elliptical. The proximal and medial portions of a left ulna reveal a platolineal form and have pronounced anterior-posterior curvature at the proximal end. The supinator crest is low. Interosseous lines are sharply defined. There is a shallow attachment for the brachial ligaments just inferior to the semilunar notch. The other ulnar and radial fragments accompany these more complete bones, each exhibiting pronounced interosseous crests. Metacarpals are limited to the distal ends of bones 2, 3, 4, and 5 of the left hand. Another bone of the left hand is the distal second phalanx.

Bones of the lower extremity include complete right and left femoral diaphyses with portions of proximal and distal ends. The lesser trochanter and neck are present in each bone. The femora are platymeric and exhibit marked anteriorposterior curvature of the diaphyses. The pilastric development is medium to pronounced, the pilaster attaining its highest point at the mid-shaft region. The lesser trochanters are not large. The left femoral cervix is elongated with a collodiaphyseal angle of 114 degrees. The left tibia is complete and the right tibia is represented only by the diaphysis. The tibial form is mesocnemic. There is pronounced anterior-posterior curvature of both shafts, especially of the left tibia. Head retroversion is slight, the vastus line is indistinct, and the tibial tuberosity is low. These features are found in highest frequencies in females. Right and left fibular diaphyses are preserved, the right fibula retaining its distal end. Slight bowing of the fibular diaphyses is present. The right lateral maleolus is robust and possesses a deep fossa for the talar ligament. Interosseous lines are low, and fluting of the shafts is absent. Right and left patellae are moderately robust and do not show osteoarthritic lipping. Right and left tali are well preserved. The os trigonum of the right talus is fused to the posterior aspect, and lateral talar extensions are prominent. But the left talus has an unfused os trigonum. Squatting facets do not appear on these tali. The medial portion of the left calcaneus can be identified amongst other fragments of the same bone and of a right calcaneus. There are portions of right and left ilia which define a wide sciatic notch as well as parts of the acetabulum.

If most of these postcranial bones belong to one individual, it is probable that this is a young adult female. Absence of osteoarthritic remodeling of postcranial bones and degrees of epiphyseal union of long bones support the estimate of an age of under 30 years. However, pronounced bowing of the long bones of the lower extremities are indicative of a pathological condition, as noted above. It is unlikely that this abnormality could be due to vitamin $\mathrm{D}$ deficiency or nutritional stress related to rickets in childhood. Presence of a treponemal disease, such as yaws, is a possible pathological factor, but a suggestion that these pathological markers are diagnostic of syphilis at Pochampad, or at any prehistoric South Asian site, would be unfounded (Rao et al. 1995).

\section{DISCUSSION AND CONCLUSIONS}

Palaeodemographers with access to skeletal samples of relatively large numbers of individuals from a specific archaeological assemblage may question the significance of studies of small skeletal series of the size encountered at Pochampad and 
adjacent Iron Age sites in peninsular India. Certainly for some measures of human biological diversity and evolutionary change, an abundance of specimens of both sexes and a broad spectrum of ages at time of death are desirable for comparative morphometric and statistical analyses. But this is not the portion alloted to the palaeoanthropologist in the recovery of the majority of prehistoric skeletons, such as hominid fossils from late Miocene to mid-Holocene antiquity for which "populations" are nonexistent. And when taphonomic agents contributing to poor preservation of osseous and dental remains are combined with poor standards of curation in certain research institutions to which excavated specimens have been transported and maintained, the scientific investigator has no choice but to accept the philosophy of the palaeontologist that you must work with what you have at hand. Alternatives are unthinkable!

Given these constraints, what has been learned about the biological anthropology of the Iron Age inhabitants of Pochampad and their contemporaries whose skeletons and dentitions have been salvaged from other megalithic burial sites in peninsular India and Sri Lanka? Answers to this question emerge from the morphometric studies conducted by trained biological anthropologists and the publication of the research results of their laboratory and statistical analyses (e.g., Kennedy 1975, 1984, 1999, 2000a, 2000b, 2000c; Kennedy and Levisky 1984; Kennedy et al. 1986; Lukacs 1985, 1992; Sarkar 1972; Walimbe 1987-1988, 1991-1992, 1992; Walimbe et al. 1991; Walimbe and Selvakumar 1998).

These investigators are aware that the physical variables and evolutionary changes they observe in skeletal series from South Asia have parallels in many other parts of the world where plant and animal domestication supplemented hunting and foraging economic strategies and essentially replaced it in urban cultural settings (Cohen and Armelagos 1984). Over the past 10,000 years since the origins of food-production practices in western Asia, those Homo sapiens populations, adapting to this new lifeway, underwent cultural changes involving sedentary village habitations, greater densities of populations in large village and later urban centers, increases in certain pathological stressers including infectious diseases, advances in technology, and changes in social organization. And accompanying these socioeconomic transitions were biological changes of which some are recorded in skeletal architecture and dental size and morphology. Large body size and greater physical stamina, which was adaptive to the hunting-foraging lifeway, particularly among males, became less critical for survival among sedentary populations whose nutritional resources came through field labor and pastoralism. Indeed, reduced body size may have been adaptive under conditions of dietary preferences with reduced consumption of flesh and dairy foods high in protein (Stini 1975), and among modern populations, taller stature and larger body mass is encountered among those societies in the northern sectors of the subcontinent where meat and milk consumption is greater than in peninsular India (Takahashi 1971). Also with the onset of the Neolithic cultural configurations there was a reduction in muscular-skeletal robusticity, as documented in skeletal morphology, and reduction of sexual dimorphism. It is probable that the evolutionary mechanism operative here was relaxed natural selection (Brace 1978, 1995).

Estimation of stature for the Pochampad series falls within the range of 1490- 
$1877 \mathrm{~mm}$ for pooled male and female adults from six Iron Age sites in India and Sri Lanka, but well above the mean of $1680 \mathrm{~mm}$ for this sample (Table 3). These estimates are based upon measurements of long bones of the upper and lower extremities and applications of the regression formulae for adult males and females of European ancestry according to a method widely used in forensic anthropology (Trotter 1970). The single stature estimate available from Pochampad is from femoral and tibial lengths of an adult skeleton of undetermined sex and indicates a body height well above that of the mean stature determined for skeletons of other Iron Age individuals.

Dental pathology is in low frequency among the preserved remains of the Pochampadians. Specimen No. Kennedy A shows severe wear along its anterior tooth row (often a consequence of use of the incisors and canines for grasping and abrasive tool-like actions and other employments of the front teeth in some habitual activity), and antemortem chipping of the posterior dentition. Specimen No. 1966, 5/6, Megalith III, has six hypoplasial lines on the right canine. Caries are not present in the Pochampad series, save for Specimen No. 1966, 5/6 (Kennedy B1), nor are cases of malocclusion, crowding, and dental calculus encountered. These are dental pathological conditions found most commonly in earlier farming and pastoral populations when compared to other ancient hunting-foraging populations within and beyond the Indian subcontinent (Lukacs 1992). Cariogenesis increases when diets are high in fermentable carbohydrates derived from sticky foods that adhere to tooth surfaces (Nelson et al. 1999; Pal 1981).

Although the cranial and postcranial bones are fragmentary in the Pochampad series, there are no observed cases of traumatic lesions inflicted by interpersonal violence or accidents. All breakage in bones and teeth are due to postmortem agents related to erosional factors, signs of predators' gnawing and dismemberment are absent. This is unexpected in cases of secondary burial.

Phenotypic variation is a conspicuous feature of peninsular India's and Sri Lanka's Iron Age populations, as elsewhere in the subcontinent. Craniological typologies do not exist, nor do earlier statements of racial identities based upon a specific set of morphometric criteria support any theory that iron was diffused to South Asia by foreign populations whose origins lay outside of this part of the world, as some biological anthropologists have proposed (Sarkar 1972). In short, phenotypic homogeneity has not been a marker of these post-Neolithic, preEarly Historic populations. Instead, heterogeneity has characterized these ironusers whose skeletons have been recovered from different regions of the subcontinent. Correlated with this evidence documented in the comparative skeletal record is the argument that there was demic continuity of the Iron Age populations of southern India and Sri Lanka with the Early Historic populations succeeding them, although regional shifts in enclaves of South Asian prehistoric peoples are likely to have taken place from time to time. The skeletal evidence does not support any hypothesis of catastrophic and sudden population replacements in peninsular India during the Iron Age.

South Asian Iron Age populations with relatively shorter histories of foodproduction practices, as indicated by radiometric and thermoluminescence dating methods and archaeological data, may retain higher degrees of muscular-skeletal 
robusticity than that encountered in other Iron Age populations with more ancient commitments to plant and animal domestication. The former retain higher frequencies of some skeletal features of greater muscular-skeletal robusticity and taller statures. Such is the nature of the skeletal series from the Iron Age burials from Timargara, Mahurjhari, Yeleswaram, and S. Pappinayakkanpatti (Fig. 1). Closely correlated with these skeletal variables characteristic of pre-Neolithic ancestry, which were preserved by those early agricultural and pastoral societies in which hunting and foraging remained a significant supplementary part of their socioeconomic strategy for survival, are changes in the sizes of crown areas of permanent molar teeth (Lukacs 1982). With respect to the summed molar crown area (as determined by calculations of squared occlusal molar crown areas of distances, measured in millimeters, of bucco-lingual and mesio-distal diameters), the range for South Asian dental series is $683-551 \mathrm{~mm}^{2}$ (Fig. 6). Three individuals from Pochampad have values of 594.43, 569.39, and 675.88 for Specimen Nos. Kennedy A, 1966, 5/5, Kennedy B1, and 1966-1964, Megalith II, respectively. The mean value of 613 is near the mean for all permanent molar dental series from other Iron Age burials, below the values for series from Pomparippu and Sarai Khola, and above the values for the series from Tadakanahalli, Kamaranahalli, Tenneru, Raipur, and Raigir (Kennedy 1997). Considering the reduced degree of muscular-skeletal robusticity of cranial and postcranial bones and relatively small permanent molar tooth size, it is hypothesized that the Pochampad population was derived from a relatively ancient lineage of pre-Iron Age farmers and herders. That is, the Pochampad community had not adapted food-production strategies during the final phases of the Iron Age and preserved those physical variables characteristic of Iron Age populations with mixed hunting-foraging and farming-herding practices which retained certain phenotypic features of their Neolithic forebears.

This thesis offers more satisfactory answers to questions of biological profiles, phenotypic diversity, genetic affinities, and evolutionary adaptations of the Iron Age peoples of South Asia than traditional notions evoking mass migrations of hordes of exotic races, often from lands beyond the Himalaya, or identifying ancient populations by their ceramic achievements to which racial typological names were assigned. Given the small size and catalog problems of the Pochampad skeletal series, the present study does not purport to be palaeodemographic in scope. Nor is it possible within the confines of this article to provide comprehensive morphometric analyses and incorporation of comparative data from all South Asian Iron Age sites, although the citations in the text and references will direct the reader to the published sources where these procedures are described. Rather, it is emphasized that small skeletal series from prehistoric localities, such as Pochampad, merit the same degree of scientific scrutiny accorded larger cemetery series because they provide the only data we shall ever have available to reconstruct the lifeways and biological profiles of extinct populations. From the Pochampad skeletal and dental data it is concluded that there was considerable phenotypic heterogeneity among Iron Age peoples of southern India and Sri Lanka, and that there was continuity of population of these last representatives of South Asian prehistory with their Early Historic successors whose cultural achievements evolved into the civilizations of Hindu, Buddhist, and Jain cultural patterns of modern times. 


\section{ACKNOWLEDGMENTS}

This research project was supported by the National Science Foundation, the Smithsonian Institution, the American Institute of Indian Studies, and Cornell University. Assisting the principal investigator in various aspects of the investigation were Mrs. Peggy C. Caldwell-Ott, Mr. William J. Roertgen, Dr. Amy Baernstein, and my wife, Mrs. Margaret C. Fairlie-Kennedy. The graphic figures were prepared by Mrs. Paula Bensadoun. Special recognition is given to Dr. V. V. Krishna Sastry of the Department of Archaeology and Museums, Hyderabad, Andhra Pradesh, and Dr. Pradeep Menehdiratta of the American Institute of Indian Studies, New Delhi. Thanks is extended to the anonymous reviews of the manuscript and to Dr. Miriam T. Stark, editor of Asian Perspectives.

\section{REFERENCES CITED}

Agrawal, D. P.

2000 Ancient Metal Technology and Archaeology of South Asia: A Pan-Asian Perspective. New Delhi: Aryan Books International.

Alur, K. K.

1979 Animal remains from Pochampad excavation 1971-72. Journal of Archaeology, Government of Andhra Pradesh 1:63-66.

Babington, J.

1823 Description of the Pandoo coolies in Malabar. Paper read at the Literary Society of Bombay on 26 December 1820. Transactions of the Literary Society of Bombay 3:324-330.

Baernstein, A., And K.A.R. Kennedy

1990 Stature variability in prehistoric and modern South Asian populations: A bio-cultural approach. Journal of Human Ecology $1: 81-108$.

BAIN, D.S.E.

1890 Antiquities of southern India. Journal of the Anthropological Society of Bombay 2:229-231.

Bose, N. K.

1959 Preliminary report on skeletal remains. Ancient India 15:40-42.

BRACE, C. L.

1978 Tooth reduction in the Orient. Asian Perspectives 19:203-252.

1995 Biocultural interaction and the mechanism of mosaic evolution in the emergence of "modern" morphology. American Anthropologist 97:711-721.

Branfill, B. R.

1881 Old slab-stone monuments in Madras and Maisur. Indian Antiquary 10:97-100.

Caldwell, P. C., and K.A.R. Kennedy

1995 Human skeletal remains from Tadakanahalli and Komaranahalli, in Sri Nagabhiaandanam: 35-77, ed. L. K. Srinavasan and S. Nagaraju. Bangalore: Government of India.

Chakrabarti, D. P.

1992 The Early Use of Iron in India. Delhi: Oxford University Press.

Chatterjee, B. K., and P. Gupta

1963 Report on the Adittanalur Skulls. Calcutta: Anthropological Survey of India.

Cohen, N. M., and G. H. Armelagos

1984 Paleopatholgy at the Origins of Agriculture. Orlando: Academic Press.

DEO, S. B.

1985 The megaliths: Their culture, ecology, economy and technolgy, in Recent Advances in Indian Archaeology: Proceedings of the Seminar Held in Poona in 1983: 89-99, ed. S. N. Deo and K. Paddayya. Poona: Deccan College.

GoOdman, A. H., AND J. C. Rose

1991 Dental enamel hypoplasias as indicators of nutritional stress, in Advances in Dental Anthropology: 279-293, ed. M. C. Kelley and C. S. Larsen. New York: Wiley-Liss. 
Gupta, P., And P. C. Dutta

1962 Human remains excavated from megaliths at Yelleswaram (Andhra Pradesh). Man in India 42:19-34.

Gupta, P., A. Basu, and P. C. Dutta

1970 Ancient human remains: Part I, A study of the Nagarjunakonda skeletons. Memoirs of the Anthropological Survey of India 20.

Indian Archaeology: A Review (IRA). Volumes for 1963-1964, 1964-1966, 1966-1967. New Delhi: Archaeological Survey of India, Government of India.

KenNedy, K.A.R.

1965 Megalithic calvariae from Raigir, Andhra Pradesh. The Anthropologist 1:1-21

1975 The Physical Anthropology of the Megalith-Builders of South India and Sri Lanka. Canberra: Australian National University Press.

1984 Growth, nutrition and pathology in changing palaeodemographic settings in South Asia, in Palaeopathology at the Origins of Agriculture: 169-192, ed. N. M. Cohen and G. J. Armelagos. Orlando: Academic Press.

1990 Skeletons in the closet: Recent discovery of lost skeletal remains from Iron Age Raigir, Andhra Pradesh. South Asian Studies 6:201-226.

1997 Skeletal adaptations of Mesolithic hunter-foragers of North India: Mahadha and Sarai Nahar Rai. International Congress of Prehistoric and Protohistoric Sciences, 1996: 291-300, ed. G. E. Afana'ev, S. Cleuziou, and J. R. Lukacs. Forli: ABACO Edizioni.

1999 Paleoanthropology of South Asia. Journal of Human Evolution 8(5) : 157-194.

2000a God-Apes and Fossil Men: Paleoanthopology of South Asia. Ann Arbor: University of Michigan Press.

2000 b Yeleswaram revisited: The skeletal record. Man and Environment 25(1):35-57.

2000 c New data for the reassessment of bio-cultural adaptations and racial affinities of Iron Age populations of South India, in South Asian Archaeology, 1997, vol. 2:617-631, ed. M. Taddei and G. De Marco. Rome: Instituto Italiano per Africa e L'Oriente.

Kennedy, K.A.R., and P. C. Caldwell

1984 South Asian prehistoric human skeletal remains and burial practices, in The People of South Asia: 159-197, ed. J. R. Lukacs. New York: Plenum Press.

KENNEDY, K.A.R., AND J. Levisky

1984 The element of racial biology in Indian megalithism: A multivariate analysis approach, in Recent Advances in Indo-Pacific Prehistory: 455-464, ed. V. N. Misra and P. Bellwood. Delhi: Oxford-IBH. (Republished 1986 in Homo: Zeitschrift für de Bergleichende Forschung a, Menschen 35:161-173.)

Kennedy, K.A.R., T. Disotell, R. J. Roertgen, and J. Shelly

1986 Biological anthropology of Upper Pleistocene hominids from Sri Lanka: Batadomba Lena and Beli Lena Caves. Ancient Ceylon 7:265-265.

Krishna SAStry, V. V.

1983 The Proto and Early Historic Cultures of Andhra Pradesh. Hyderabad: Government of Andhra Pradesh.

KNUSSMANN, R.

1988 Anthropologie Handbuch der vergleichenden Biologie des Menschen 1(1). Stuttgart: Gustav Fischer Verlag.

Kumar, S. S., I. Nasidze, S. R. Walimbe, and M. Stoneking

2000 Brief communication: Discouraging prospects for ancient DNA from India. American Journal of Physical Anthropology 113:129-133.

Lukacs, J. R.

1976 Dental anthropology and the biological affinities of an Iron Age population from Pomparippu, Sri Lanka, in Ecological Backgrounds of South Asian Prehistory: 197-215, ed. K.A.R. Kennedy and G. L. Possehl. Occasional Papers and Theses of the South Asia Program, Cornell University 4.

1982 Cultural variation and the evolution of dental reduction: An interpretation of the evidence from South Asia, in Human Genetics and Adaptation, vol. 2:252-269, ed. A. Basu and K. C. Malhotra. Proceedings of the Indian Statistical Institute Golden Jubilee International Conference, Calcutta.

1983 Human dental remains from early Neolithic levels at Mehrgarh, Baluchistan. Current Anthropology $24: 390-393$.

1985 Tooth size variation in prehistoric India. American Anthropologist 87:811-825. 
1992 Dental paleopathology and agricultural intensification in South Asia: New evidence from Bronze Age Harappa. American Journal of Physical Anthopology 87:133-150.

LESHNIK, L. S.

1974 South Indian "Megalithic" Burials: The Pandukal Complex. Weisbaden: Franz Steiner.

MurTy, P. R.

1965- Unpublished manuscript. Department of History and Museums, Hyderabad, Government

1973 of Andhra Pradesh.

Nagaraja Rao, M. S.

1971 Protohistoric cultures of the Tungabhadra Valley: A Report on Hallur Excavations. Bangalore: Eastern Press.

1981 Earliest iron-using people in India and the megaliths, in Mandu: Recent Researches in Indian Archaeology and Art History: 25-32, ed. M. S. Nagaraja Rao. Delhi: Agam Kala Prakashan.

Nelson, G. C., J. R. Lukacs, and P. Yule

1999 Dates, caries and early tooth loss during the Iron Age of Oman. American Journal of Physical Anthropology 108:333-343.

PAL, A.

1981 Dental health in ancient India. Journal of the Indian Anthropological Society 16:171-177.

Possehl, G. L., AND P. C. Rissman

1992 The chronology of prehistoric India from earliest times to the Iron Age, in Chronologies in Old World Archaeology, vol. 1: 465-490; vol. 2: 447-474, ed. R. W. Ehrich. Chicago: University of Chicago Press.

Possehl, G. L., and P. Gullapalli

1999 The early Iron Age in South India, in The Archaeometallurgy of the Asian Old World: 153175, ed. V. Piggott. The University of Pennsylvania Monograph 89; MASCA Research Papers in Science and Archaeology 16. Philadelphia.

RAO, K. R.

1988 Deccan Megaliths. Delhi: Sundeep Prakashan.

Rao, V. V., T. S. Vasulu, and A.D.W. Rector Babu

1996 Possible paleopathological evidence of treponematosis from a megalithic site at Agripalle, India. American Journal of Physical Anthropology 100:49-55.

Rivet-Carnac, J. H.

1879 Prehistoric remains in central India. Journal of the Asiatic Society of Bengal 48:1-16.

STINI, W. A.

1975 Adaptive strategies of human populations under nutritional stress, in Biosocial Relations in Population Adaptation 19-41, ed. E. E. Watts, F. E. Johnston and G. W. Lasker. The Hague: Mouton.

Subrahmanyam, B. R.

1987 Iron Age in Andhra Pradesh, in Archaeology in Andhra Pradesh. Victoria Jubilee Museum Vijayaswada Centenary, 1887-1987: 13-16, ed. V. V. Krishna Sastry. Hyderabad, Government of Andhra Pradesh.

TAKahashi, E.

1971 Geographic distribution of human stature and environmental factors: An ecologic study. Journal of the Anthropological Society of Nippon 79:259-286.

TrotTer, M.

1970 Estimation of stature from intact long bones, in Personal Identification in Mass Disasters: 7183, ed. T. D. Stewart. Washington, D.C.: Smithsonian Institution.

WALIMBE, S. R.

1987- Human skeletal remains from megalithic Vidarba. Puratattva 18:61-71.

1989

1991- Human skeletal evidence from megalithic Raipur. Bulletin of the Deccan College Research

1992 Institute 51-52:667-668.

1992 Human skeletal evidence from megalithic Raipur, in Megalithic Raipur (1985-1990): 125-132, ed. G. B. Deglurkar and G. P. Lad. Poona: Deccan College.

Walimbe, S. R., P. B. Gambhir, and P. C. Venkalasubbaiah

1991 A note on megalithic human skeletal remains from Kanyathirtham, Cuddapah District, Andhra Pradesh. Man and Environment 16:99-101. 
Walimbe, S. R., and V. Selvakumar

1998 Anthropological investigation of an Iron Age adult male skeleton from S. Pappinayakkanpatti, Madurai district, Tamil Nadu. Journal of Human Ecology 9:19-34.

WHEELER, R.E.M.

1947- Brahmagiri and Chandravalli 1947: Megalithic and other cultures in the Chitraldrug dis1948 trict, Mysore state. Ancient India 4:180-310.

\section{ABSTRACT}

Human skeletal remains from a burial site in southern India excavated in the 1960s by the Department of Archaeology and Museums of the Government of Andhra Pradesh, Hyderabad, have been analyzed. The burials were recovered from three megalithic graves containing iron weapons and horse trappings, pottery and terracotta figurines, stone blades, pieces of copper, and faunal remains of domesticated species. These assemblages are hallmarks of the southern Indian Iron Age (Megalithic period) of the last three centuries B.C. Laboratory examination of the human skeletal and dental remains provide new information concerning the phenotypic heterogeneity of Iron Age populations, their physical changes in stature and tooth size, reduction of muscular-skeletal robusticity and sexual dimorphism, and other biological features reflecting evolutionary adaptations from an ancestral huntingforaging lifeway to settlement in sedentary villages. The data from the study of the skeletal-dental biology of the inhabitants of Pochampad offer new insights into the health status and profiles of growth and development of these and other Iron Age populations in this part of the world. It is concluded that there was considerable phenotypic heterogeneity among these Iron Age communities of southern India and Sri Lanka, and that there was a continuity of populations over time rather than any abrupt demographic displacement of earlier Neolithic populations by invasions of some foreign, early iron-using peoples. Similarly, the biological data suggest that there was continuity of populations and gradual emergence of these last representatives of South Asian prehistory with their Early Historic period successors. KeYwords: Indian Iron Age, megalithic burials, biological anthropology. 